\title{
Kinetic energy from distributed wind farms : technical potential and implications
}

\section{Citation for published version (APA):}

Rawn, B. G., Gibescu, M., \& Kling, W. L. (2010). Kinetic energy from distributed wind farms : technical potential and implications. In Proceedings of the 2010 IEEE PES Conference on Innovative Smart Grid Technologies Conference Europe (ISGT Europe ), 11-13 October 2010, Gothenburg, Sweden (pp. 1-8). Institute of Electrical and Electronics Engineers. https://doi.org/10.1109/ISGTEUROPE.2010.5638972

DOI:

10.1109/ISGTEUROPE.2010.5638972

Document status and date:

Published: 01/01/2010

\section{Document Version:}

Publisher's PDF, also known as Version of Record (includes final page, issue and volume numbers)

\section{Please check the document version of this publication:}

- A submitted manuscript is the version of the article upon submission and before peer-review. There can be important differences between the submitted version and the official published version of record. People interested in the research are advised to contact the author for the final version of the publication, or visit the $\mathrm{DOI}$ to the publisher's website.

- The final author version and the galley proof are versions of the publication after peer review.

- The final published version features the final layout of the paper including the volume, issue and page numbers.

Link to publication

\section{General rights}

Copyright and moral rights for the publications made accessible in the public portal are retained by the authors and/or other copyright owners and it is a condition of accessing publications that users recognise and abide by the legal requirements associated with these rights.

- Users may download and print one copy of any publication from the public portal for the purpose of private study or research.

- You may not further distribute the material or use it for any profit-making activity or commercial gain

- You may freely distribute the URL identifying the publication in the public portal.

If the publication is distributed under the terms of Article 25fa of the Dutch Copyright Act, indicated by the "Taverne" license above, please follow below link for the End User Agreement:

www.tue.nl/taverne

Take down policy

If you believe that this document breaches copyright please contact us at:

openaccess@tue.nl

providing details and we will investigate your claim. 


\title{
Kinetic Energy from Distributed Wind Farms: Technical Potential and Implications
}

\author{
Barry G. Rawn, Student Member, IEEE, Madeleine Gibescu, Member, IEEE, Wil L. Kling, Member, IEEE
}

\begin{abstract}
This paper presents an assessment of the kinetic energy reserve that could be made available by aggregating a distributed group of wind farms. The size of reserve available for a single turbine and the range of wind speeds where it can be assumed available is computed and compared with the kinetic energy delivered by synchronous generators during typical transients. The size and availability of an aggregated reserve is then computed using wind speed data from 39 locations on and off the shores of the Netherlands. The dependence of this reserve on the area and density of sites being aggregated is presented. Finally, the aggregated reserve is compared on a statistical basis with the energy required for 87 frequency dip incidents in the European continental grid. It is concluded that although improved communications and control would be necessary, the technical potential could meet or exceed the need for inertial response forty percent of the time.
\end{abstract} kets

Index Terms-wind power generation, inertia, real-time mar-

\section{INTRODUCTION}

\section{A. Background}

Reliable power systems require a sufficient amount of reserve energy to rectify imbalances between supply and demand. A diversity of information about load characteristics and generator scheduling is employed for assessing this need, and communication networks are employed to procure and monitor the deployment of this energy when it is needed. The evolution of a smart grid will entail expansion of the extent and rate of comunications. Many of the new devices being interconnected with the grid offer increased rate of response and fineness of control due to power electronic interfaces. This can lead to greater flexibility in both supply and demand.

With a shift to a larger number of electricity generating sources in new locations that tap variable sources of energy such as wind and solar, future power systems will involve more uncertainty and complexity. The new mixture of sources will also change how devices contribute to regulating the frequency of the power system. A crucial aspect of system stability is the amount of kinetic energy present in the rotating machines connected to the grid. Whenever a sudden increase in load or decrease in generation occurs, the imbalance is drawn from

This research is part of the project RegelDuurzaam, which is funded under the SenterNovem program EOS-LT. SenterNovem is an agency of the Dutch Ministry of Economic Affairs.

Barry Rawn, Madeleine Gibescu and Wil Kling are with the Department of Electrical Sustainable Energy, Delft University of Technology, 2600 CD Delft, The Netherlands (e-mails:b.g.rawn@tudelft.nl, m.gibescu@tudelft.nl, w.1.kling@tudelft.nl).

Wil Kling is also with the Electrical Power Systems Group, Eindhoven University of Technology, 5612 AZ Eindhoven, The Netherlands (e-mail: w.1.kling@tue.nl) this kinetic energy for the duration of the delay required for other sources of generation to ramp up their production. This effect is referred to as primary or inertial response. It is provided by default by synchronous machines, but it has been observed that in island power systems specific assessment and procurement of this type of reserve may be necessary [6].

Distributed wind farms are expected to serve a significant fraction of demand in power systems around the world. During periods when a large part of the online power capacity of grid is made up of wind farms, the availability of kinetic energy in the case of a contingency becomes a concern. This is because wind turbines do not normally provide an inertial response. They can be controlled to do so, but the size and availability of the response varies with wind speed. The amount of wind power available from a farm is monitored and to some extent forecast. However, the kinetic energy available from a distributed fleet of wind farms facing different operating wind conditions has not been measured or subjected to analysis. In power systems equipped with the advanced information gathering and actuation capabilities of a smart grid, it will likely become possible to monitor and exploit this resource.

\section{B. Contribution of the paper}

In this paper, wind speed time series from 39 onshore and offshore locations have been analyzed to assess the availability of kinetic energy reserve from an aggregation of wind farms. The dependence of the availability and quantity of the energy on area, distance, and density of sites is examined. Time variations and general statistics are presented and compared to the kinetic energy involved in 87 frequency transients in the European continental grid. A future scenario for wind power in the Netherlands is used to assess technical potential for a realistic case. Finally, the applications for a smart grid are discussed.

\section{Kinetic Energy Deliverable by Wind Turbines}

\section{A. Control Scheme}

Several methods have been proposed for wind turbines to contribute to support frequency during a contingency. Some approaches apply a frequency feedback loop that causes the wind turbine to deliver a power pulse or other waveform, by controling generator torque. In these approaches, the turbine still operates with maximum power tracking, so that energy is only temporarily injected and then reabsorbed, with no net change to the operating speed of the turbine [10]. This has the effect of reducing the rate of change of frequency at the onset 


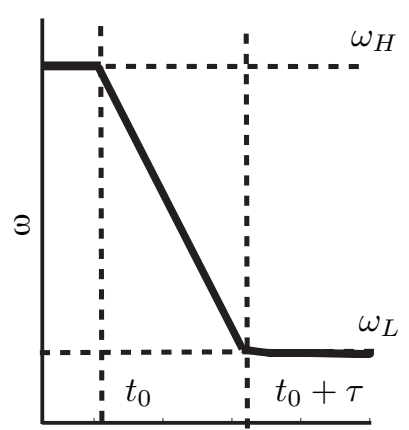

Time

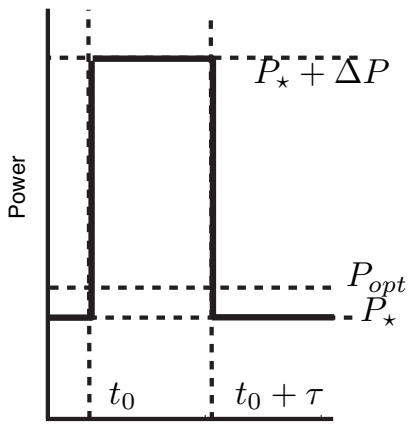

Time

(b) Power (a) Rotational speed

Fig. 1. Illustration of kinetic energy reserve due to de-rating.

of the event, possibly at the expense of a deeper frequency dip. It has also been proposed to reverse this tradeoff [8]. In that case, turbines exacerbate the rate of change of frequency by first absorbing energy, but then return it to result in a lower overall dip.

The turbine can instead be controlled via generator torque to drop its speed from an operating point $\omega_{H}$ to a new operating point $\omega_{L}$, in response to a frequency drop, injecting the energy associated with the speed difference without re-absorption[2]. This is depicted in Fig. 1(a). If the turbine is controlled appropriately, then it can inject this energy and still deliver the same power level $P^{\star}$ before and after the event (Fig. 1(b)). However, the power level $P^{\star}$ is necessarily less than the optimal power $P_{\text {opt }}$ available from the wind, as will be explained in the next section. This technique therefore has the drawback of wasting some available wind energy, but has the benefit of supporting frequency in a manner similar to a synchronous machine.

It has also been proposed to apply both generator torque and pitch control to regulate the operating speed of the turbine at a value close to rated speed [4]. The power output and operating range would likely be strongly altered. Such a technique makes the maximum amount of kinetic energy available, but wastes significant amounts of wind energy. Therefore this paper applies the approach of contributing a fixed amount of energy as depicted in Fig. 1.

\section{B. Upper Bound: Kinetic Energy $\Delta E_{k}\left(v_{w}, \lambda_{H}\right)$ at Constant Wind Speed}

De-rated operation exploits the variable conversion efficiency of the wind turbine blades. This efficiency is characterized by the curve $C_{p}(\lambda)$, where $\lambda$ is the ratio of blade tip-speed to wind speed:

$$
\lambda=\frac{R \omega}{v_{w}}
$$

where $R$ is the blade radius, $\omega$ is the turbine rotor rotational speed and $v_{w}$ is the wind speed. For a given wind speed, the turbine extracts maximum power when $\lambda=\lambda_{\text {opt }}$, as depicted in Fig. 2. For the same wind speed, if the rotor speed $\omega$ is maintained such that $\lambda=\lambda_{H}$, then the turbine operates at a

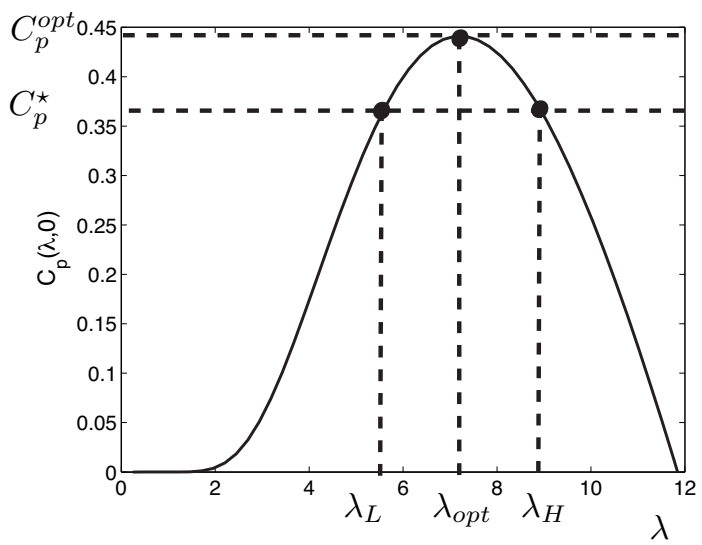

Fig. 2. De-rated operating philosophy, shown on power conversion efficiency curve $C_{p}(\lambda)$. Operation occurs not around optimal tip-speed ratio $\lambda_{o p t}$, but around $\lambda_{H}$ at a de-rated efficiency $C_{p}^{\star}$. A reserve of kinetic energy is made availble between $\lambda_{H}$ and $\lambda_{L}$.

de-rated efficiency $C_{p}^{\star}$, associated with a de-rated power $P^{\star}$. A power greater than or equal to this level can be provided not just at one unique speed, but over a whole rotor speed range:

$$
\left[\omega_{L}, \omega_{H}\right]=\left[\frac{v_{w} \lambda_{L}}{R}, \frac{v_{w} \lambda_{H}}{R}\right]
$$

Consider operation at a wind sped $\bar{v}_{w}$. A change in rotational energy up to the quantity

$$
\Delta E_{K}\left(\bar{v}, \lambda_{H}\right)=\frac{1}{2} J\left(\frac{\bar{v}}{R}\right)^{2}\left(\lambda_{H}^{2}-\lambda_{L}^{2}\right)
$$

where $J$ is the inertia of the turbine rotor, can be extracted and delivered into the grid, while returning to a level of power equal or greater $P^{\star}$. The relation 3 only applies in a certain range of wind speeds. Above rated wind speed, turbines are usually controlled to have constant rotor speed and deliver rated power. More restrictively, the minimum and maximum speed limits and torque limit of the wind turbine dictate a narrower range of wind speeds within which the rotor can operate continuously at $\omega_{H}$, yet also drain to $\omega_{L}$ whenever necessary [7]. One can select the pulse time $\tau$ sufficiently long to avoid the torque limit [7] so that the possible range $\left[v_{\min }, v_{\max }\right]$ of wind speeds depend only on the machine speed limits:

$$
\begin{aligned}
& v_{\text {min }}=\frac{R}{\lambda_{L}} 1.1 \omega_{\text {min }} \\
& v_{\text {max }}=\frac{R}{\lambda_{H}} 0.9 \omega_{\text {rated }}
\end{aligned}
$$

where $\omega_{\text {min }}$ and $\omega_{\text {rated }}$ are the minimum and rated rotor speeds, and the factors 1.1 and 0.9 reflect a margin away from these speeds. In Fig. 3, the kinetic energy $\Delta E_{K}\left(\bar{v}, \lambda_{H}\right)$ is plotted over its proper range $\left[v_{\min }, v_{\max }\right]$ to show the upper bound on kinetic energy available from a wind turbine, assuming a fixed wind speed.

\section{Practical Estimate: Minimum Reserve $E_{K R}\left(\bar{v}_{w}, \lambda_{H}\right)$ over 10 minute Interval}

Any assessment of the technical potential of kinetic energy from wind turbines must take some account of wind varia- 


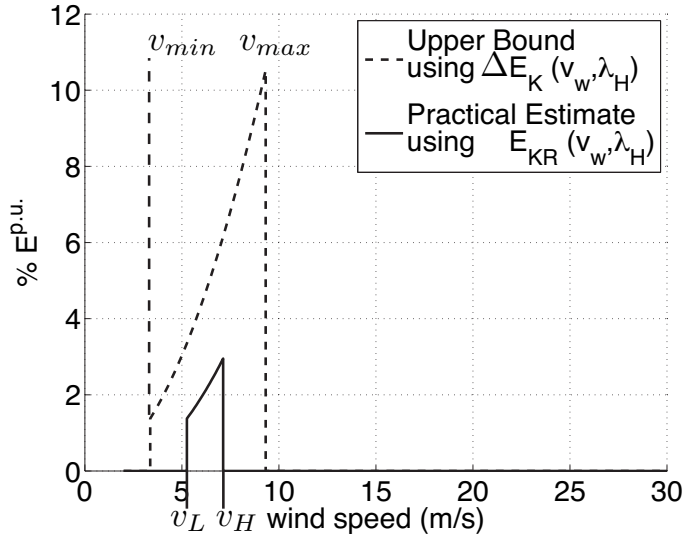

Fig. 3. Quantity of kinetic energy available as function of operating wind speed. Upper bound (dashed) is determined by machine speed and torque limits, while practical estimate (solid) is derived based on conservative assumptions.

tions. For wind speeds measured at a point, it is known that the distribution about a 10 minute mean speed is Gaussian [11],[1].

The equivalent wind speed that must be used to model the action of the wind input on the shaft torque of a wind turbine will have a different distribution. Due to the spatial averaging of the rotor disc, the distribution will certainly have a smaller standard deviation. However, properly accounting for this effect requires a good model of the rotor disc effect, which was unavailable at the time of the study. The approach presented in this paper therefore uses only the intersections of torquespeed curves, and does not employ differential equations. The approach makes several assumptions to derive a conservative estimate of the minimum reserve energy available.

A band of wind speed values about a mean value $\bar{v}_{w}$ within a ten-minute period is defined by:

$$
\bar{v} \pm n_{\sigma} \sigma(\bar{v})=\bar{v}\left(1 \pm n_{\sigma} I_{15} \frac{a+\frac{15}{\bar{v}}}{1+a}\right)
$$

where $n_{\sigma}$ is the number of standard deviations accounted for, $I_{15}$ has high and low values of 0.12 and 0.16 , and $a$ has values between 2 and 3 [1], corresponding to the IEC turbulence classes $\mathrm{C}$-A respectively.

The most extreme values of the wind speed distribution do not translate into rotor speed variations, so in this paper it is assumed that the most extreme $10 \%$ of wind speed values can be discarded. A conservative value of $n_{\sigma}=1.65$ was thus chosen to define the band of likely wind speed variations.

The ability to deliver kinetic energy could be required at any instant during a ten minute interval. The range of expected availability must be narrowed to ensure that a known quantity of energy will always be deliverable regardless of the possible range of wind variations. The minimum possible wind speed determines the minimum available kinetic energy reserve.

In this paper, the practical range $\left[v_{L}, v_{H}\right]$ is computed as

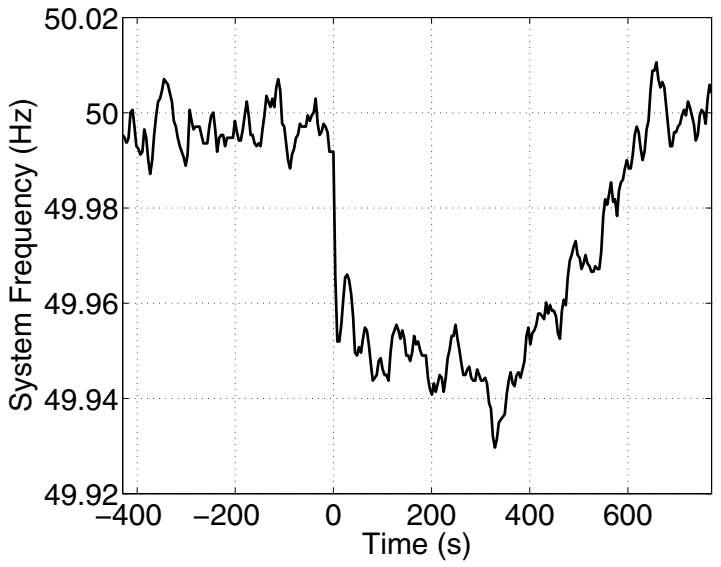

(a) Frequency transient

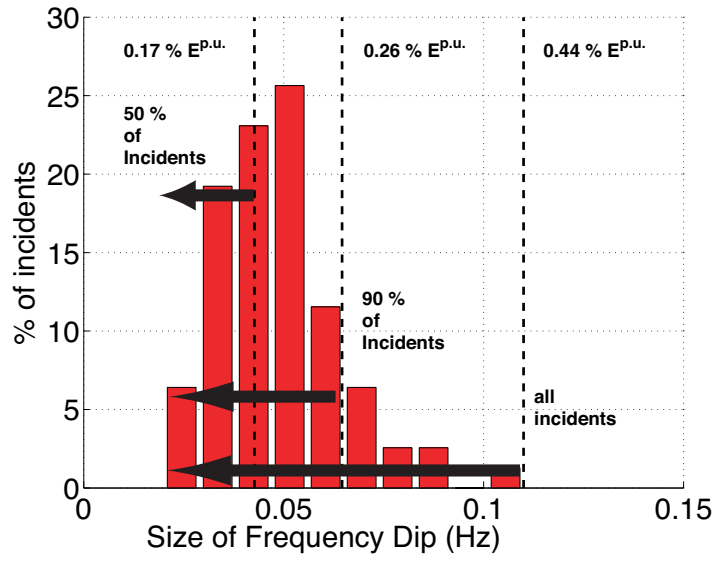

(b) Distribution of minimum values

Fig. 4. Frequency incidents in continental European grid.

follows

$$
\begin{gathered}
v_{L}=\frac{v_{\min }+n_{\sigma} \frac{I_{15}}{1+a}}{1-n_{\sigma} \frac{I_{15}}{1+a} a} \\
v_{H}=\frac{v_{\max }-n_{\sigma} \frac{I_{15}}{1+a}}{1+n_{\sigma} \frac{I_{15}}{1+a} a}
\end{gathered}
$$

and the minimum possible reserve for wind speeds in $\left[v_{L}, v_{H}\right]$ is:

$$
\left.E_{K R}\left(\bar{v}, \lambda_{H}\right)\right)=\frac{1}{2} J\left(\frac{\bar{v}-n_{\sigma} \sigma(\bar{v})}{R}\right)^{2}\left(\lambda_{H}^{2}-\lambda_{L}^{2}\right)
$$

where $\bar{v}$ is ten-minute mean, $\sigma(\bar{v})$ is the standard deviation for that mean value, $n_{\sigma}$ is the number of standard deviations included, $J$ is the turbine inertia, and $\lambda_{L}$ is such that $C_{p}\left(\lambda_{\star}\right)=$ $C_{p}\left(\lambda_{L}\right)$.

\section{Selection of $\lambda_{H}$ for Maximum Kinetic Reserve}

The quantity of de-rating is determined by how far $\lambda_{H}$ is from $\lambda_{\text {opt }}$. De-rating decreases the available range $\left[v_{L}, v_{H}\right]$, but increases the minimum kinetic reserve $E_{K R}\left(\bar{v}_{w}, \lambda_{H}\right)$. For a given turbine and wind resource as characterized by Weibull parameters, $\lambda_{H}$ can be selected to maximize the total kinetic reserve offered over a year [7]. 


\section{E. Comparison with Required Energy}

The kinetic energy present in a generator rotating at rated speed is

$$
E^{p . u .}=\frac{1}{2} J \omega_{\text {rated }}^{2}
$$

and it is often reported as the scaled value $H$ [5]:

$$
H=E^{\text {p.u. }} / S_{\text {rated }} \text {. }
$$

which conveniently has units of seconds. The $\mathrm{H}$ value of a wind turbine, ranging from 3-4s [9], is similar to that of large synchronous machines, which changes depending on the units in operation and can range from 2-7s [5]. Suppose a synchronous machine is replaced by a wind farm of equal name-plate capacity. Because they have similar $\mathrm{H}$ values, it follows through (11) that these two generators also have similar $E^{p . u}$ bases. This paper expresses changes in kinetic energy of both synchronous machines and wind turbines as a percentage of $E^{\text {rated: }}$

$$
\% E^{p . u}=\frac{\Delta E_{k}}{E^{\text {rated }}} \cdot 100 \%
$$

If a wind farm or an aggregate of wind farms can deliver a percentage of its $E^{p . u}$ equal to that of a synchronous machine, then it has delivered the same amount of actual energy.

Consider a typical contingency in the European continental grid is shown in Fig. 4(a). All such recorded transients from the period 2004-2006, comprising 87 incidents, were obtained from the Dutch TSO TenneT. At time $t=0$, the frequency drops almost $50 \mathrm{mHz}$ within 8 seconds. The quantity of energy involved in this initial transient is the one being investigated, and can simply be computed from the speed change associated with the difference $50 \mathrm{~Hz}-49.95 \mathrm{~Hz}$. This $0.1 \%$ speed change is only $0.2 \%$ on the $E^{p . u}$ basis. In Fig. 4(b), a histogram shows the distribution of minimum frequency during frequency incidents. Vertical dashed lines indicate how much kinetic energy in the per-unit basis $\% E^{p . u .}$ is associated with such a change in speed. These levels of energy are noted in subsequent figures of this paper to provide a comparison.

Unlike a synchronous generator, the speed of turbines in a wind farm vary considerably. While a wind turbine often operates below rated speed, it is also free to change its speed asynchronously over a wide range. Fig. 3 shows that a wind turbine has the potential to deliver significantly more energy than a synchronous machine during a contingency (e.g. at least $1-2 \%$ v.s. $0.44 \%$, and that a single machine is not always available.

\section{Study Data, Assumptions, And Method}

To investigate the technical potential for kinetic energy in a large aggregation of wind farms, year-long wind speed data series consisting of 10 minute averages from 39 onshore and offshore locations in the Netherlands were used to represent an average farm wind speed at these locations. These time series were generated based on data from weather stations, using appropriate techniques for extrapolation to hub height and spatial interpolation [3]. The locations are actual or proposed wind farm sites, and are shown in Fig. 5. The installed capacities of the sites are based on existing, approved, and

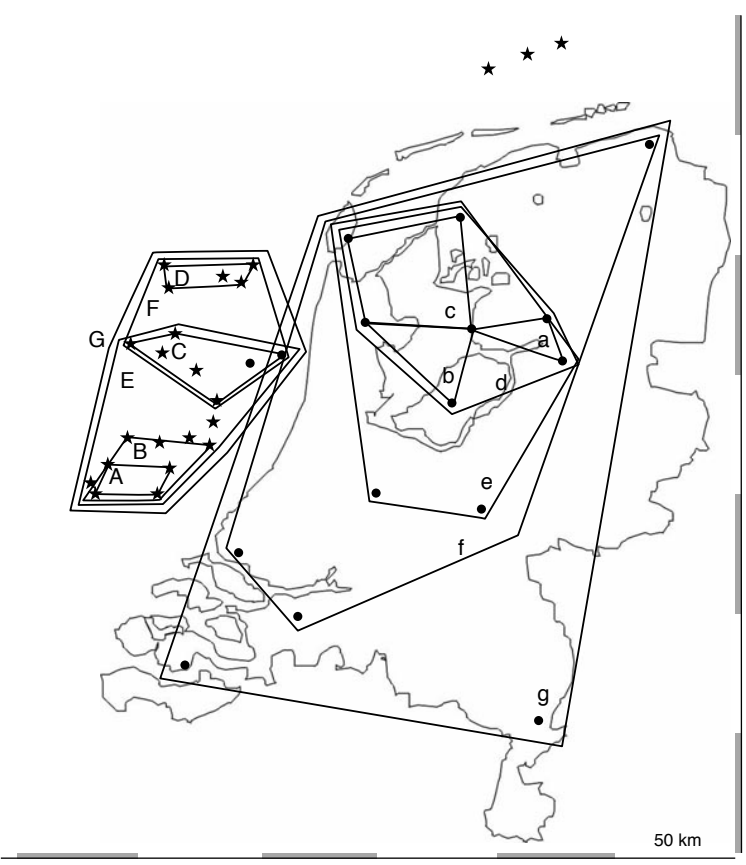

Fig. 5. Locations of wind farm sites superimposed on map of Netherlands, and areas studied. Stars indicate future sites, while circles indicate currently installed capacity.

proposed projects. Existing onshore sites were scaled up to a future repowered capacity of $4 \mathrm{GW}$, and future offshore capacity equals $6 \mathrm{GW}$. It is assumed that all wind turbines at a given site $i$ experience the same wind speed, so that the quantity of energy available from a farm can be obtained by multiplying the energy available from a single turbine by the number of turbines $n_{i}$.

Offshore sites were assigned 3 MW E-101 machines, while the onshore sites were assigned 2 MW E-82 machines. The wind turbine models selected for this study were chosen because of their wide rotational speed ranges, which were both more than $3: 1$, as is expected in future machines. Rotor and wind speed ranges are available from product brochures, and a standard $C_{p}$ curve was assumed [9]. The wind speed distributions off offshore sites had Weibull parameters close to $c=10.8, k=2.2$. For such a resource the E-101 produces approximately nearly half its energy in rated mode, and that machine is therefore a reasonable fit to the site. The onshore sites had a wider range of parameters; the average values of $c=7.2, k=1.85$ did not match the designed IEC class of most models available. As a result, these turbines spend more time than normal in the below-rated range. The de-rating for each type of turbine was selected to maximize the amount of kinetic energy made available. For the E-101 a de-rating of $3 \%$ was identified as maximizing yearly kinetic reserve. A de-rating of $1 \%$ as optimal for the E- 82 .

Using the techniques of the preceeding section, ten-minute mean wind speeds time series can be converted to kinetic reserve time series, and summed to investigate different combinations of sites, as depicted in Fig. 6. In the figure, $n_{i}$ and $E_{i}^{p . u .}$ refer to the number of turbines and kinetic energy base 


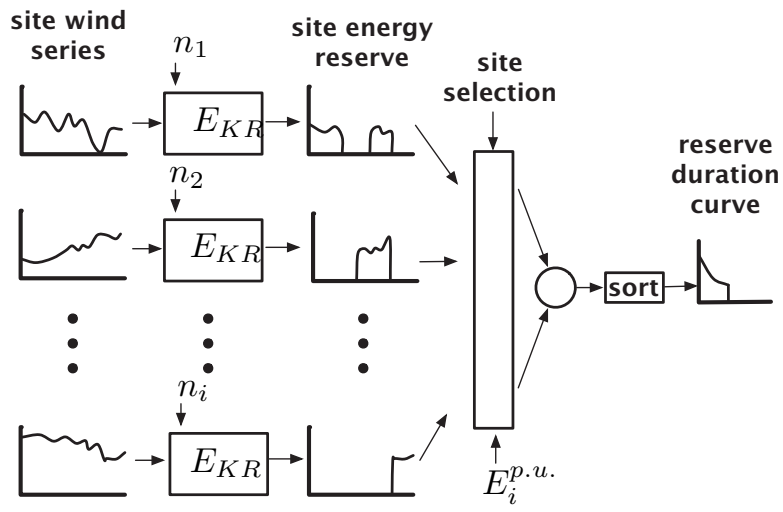

Fig. 6. Computation framework of the study.

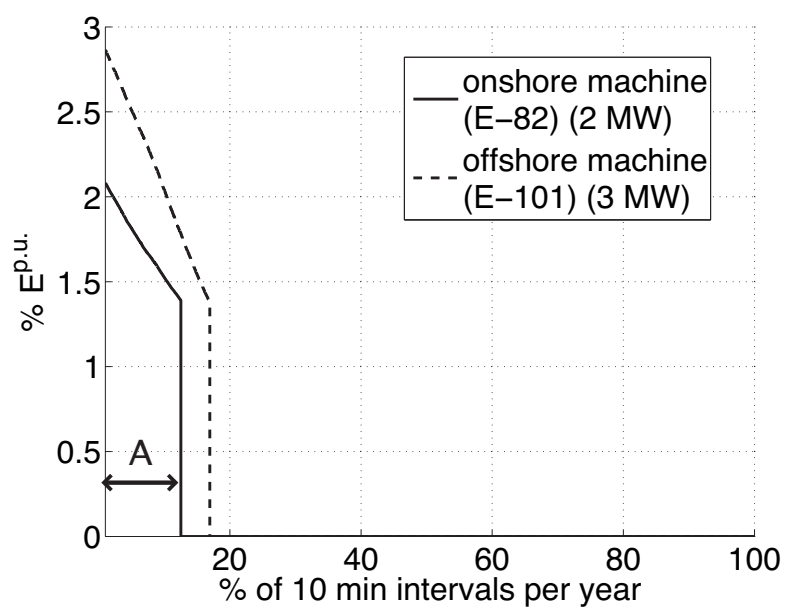

Fig. 7. Duration curves of available kinetic energy from turbine model used in onshore and offshore representations.

value at site $i$. This paper presents most results in the form of duration curves, which show the possible range of reserve available for an aggregation of sites, and the fraction of time it is available:

$$
\begin{aligned}
A_{i}(k) & =\left\{\begin{array}{cc}
1 & v_{L}<\bar{v}_{w}(k)<v_{H} \\
0 & \text { otherwise }
\end{array}\right. \\
A_{\text {agg }} & =\frac{1}{52560} \sum_{k=1}^{52560} \operatorname{sgn}\left(\sum_{i \in S} A_{i}(k)\right) \cdot 100 \%
\end{aligned}
$$

where $A_{a g g}$ is the availability of an aggregation of sites (as opposed to a single site, which is denoted by $A$ ), sgn is the signum function, 52560 can be recognized as the number of 10 minute intervals in a year, $A_{i}(k)$ is the availability vector of the $i t h$ site, and $S$ is the set of sites. The dependence of the availability $A$ on different aspects will also be investigated. The quantity A

Fig. 7 shows duration curves of the quantity of kinetic energy available when the E-101 is placed at an offshore site, and the E- 82 is placed at an onshore site. The energy has been expressed as a percentage of the kinetic energy of the machine at rated speed. The availability A is depicted graphically on the duration curve.

\section{RESUlTS}

Using the assumptions and techniques stated in the previous section, one can investigate the basic features of the technical potential of a distributed set of wind farms. Based on actual and projected farm sizes, one can also quantify this technical potential for the Netherlands and compare the properties of this resource against the needs posed by typical disturbances in the European continental grid.

\section{A. Basic Features}

In Fig. 8(a), the available kinetic energy per turbine is shown for a single site over three hours. A trace along the zero line marks those 10 minute intervals where no kinetic energy reserve is available. For comparison, the maximum quantity of energy that would be injected by a synchronous machine during any of the 2004-2006 contingencies is plotted as a dashed line. A similar quantity of energy is sometimes available from the wind turbine, but often no energy is available, because the wind speed at that site is outside the necessary range. Around hour 10 and 27 of the figure, long gaps in availability are present. In Fig. 8(b), the available kinetic energy is depicted for two other sites, at significant distance from the first. Each of these sites fills one of the gaps present in Fig. 8(a). This way well reflect the transit of a wind mass with appropriate wind speed ranges as it passes through the area being tapped. The effect of reduced variability from wind power as geographical area of wind installations increases is well known. Similarly, an increased availability of kinetic energy reserve can also be observed when sites in geographically spread locations are tapped. In Fig.9(a), this dependence is shown to be logarithmic. Offshore and onshore sites are shown separately. From the duration curve of Fig. 9(b), it appears that increasing availability is traded for a distribution of lower reserve. Large reserves become a smaller fraction of total intervals per year.

Besides the effect of increased distance between sites, the number of sites is also playing a role in the results of Fig. 9. This effect can be isolated by considering the density of sites. In the curves of Fig. 10(a), area is held constant and the availability is assessed for different numbers of sites within that area. The sites have been selected to be as uniformly spaced as possible. Density increases availability, but the maximum availability depends on the area involved.

As the number of sites increases within a fixed area, a diversity of distances develops, and the minimum distance between any two sites decreases. Each curve in Fig. 10(a) has a knee point, indicating a density beyond which additional sites stop improving availability. This may be because the minimum distance between sites reaches a special value.

The form of duration curve is altered in different ways by increasing density, versus increasing area. In Fig. 9(b), both the maximum amount of reserve and availability change. In Fig. 10(b), the slope of the duration curve stays the same while the availability threshold is pushed out with increasing density.

\section{B. Aggregate Netherlands Example}

The effect in the time domain of aggregating onshore (14 sites) and offshore kinetic energy ( 25 sites) is shown in Fig. 11, 


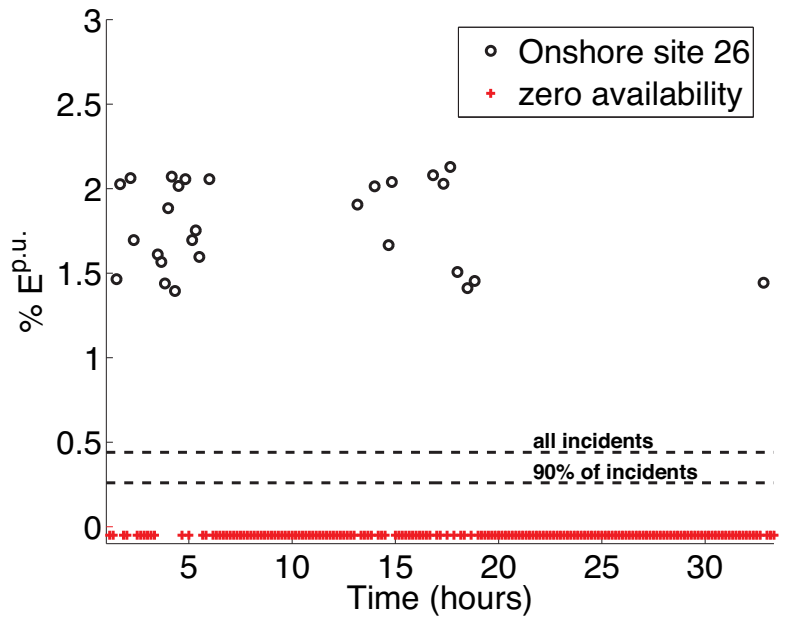

(a) One turbine.

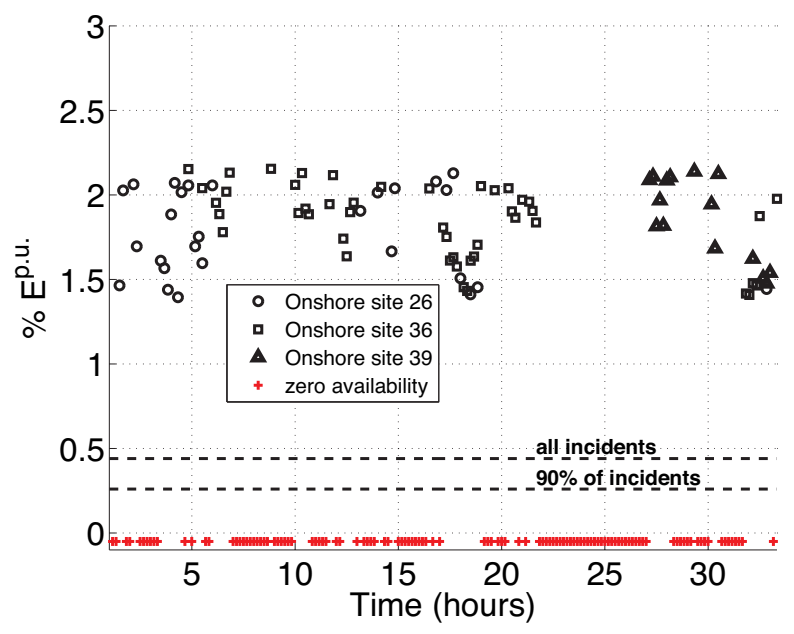

(b) Three turbines.

Fig. 8. Kinetic energy available from individual turbines over three hour period.

for a 10-day sequence. For each aggregate, there are periods with duration of hours or a half a day where some kinetic energy is always available, in contrast to the three-site or one site time domain plots of Fig. 8(a) and 8(b), where availability within an hour could not be guaranteed. However, periods of unavailability also exist. Over the days 2-4 shown in the figure, the availability of offshore and onshore sites is complementary, likely the effect of weather propagation patterns. However, there are still periods where no kinetic energy is available from any site. Due to the form of the curves in Fig. 3, it could be that the farms are producing full power with no capacity to supply kinetic energy. Thus it is conceivable that it is precisely those times when wind turbines compose a large fraction of generation, and need to also provide kinetic energy, that they cannot.

A duration curve of the year-round available kinetic energy (Fig. 12) shows that, compared to individual turbines (Fig. 7, the availability of the aggregate kinetic energy is higher, but it has on average a smaller range, which does not often exceed $1 \%$ of the rated amount of kinetic energy. On a percentage basis the aggregate duration curve will not equal the sum of

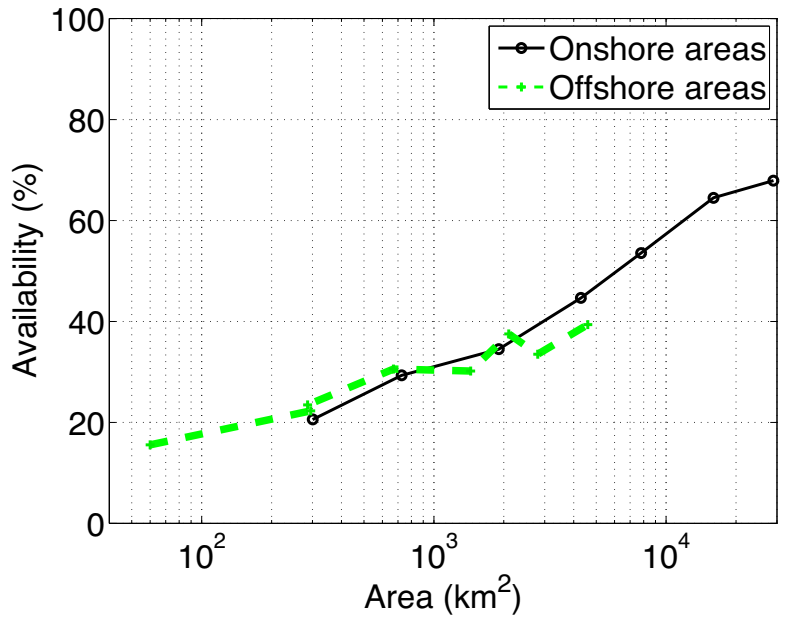

(a) Availability for offshore areas A-G and onshore areas a-g.

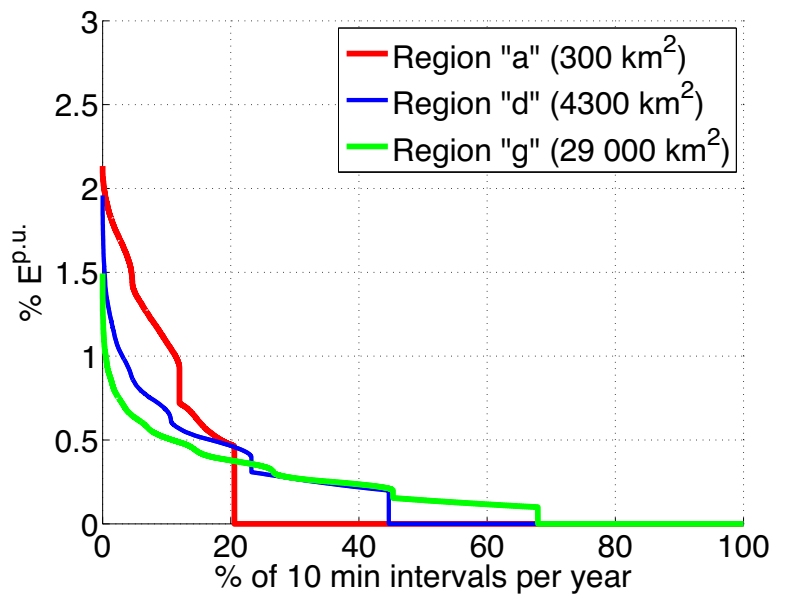

(b) Family of kinetic energy duration curves for selected onshore regions.

Fig. 9. Dependence of kinetic energy availability on area.

the offshore and onshore curves. This is because the largest contributions of offshore and onshore will not necessarily coincide (as can be observed from Fig.11).

When compared with the actual size of incidents experienced in the European continental grid, this quantity of energy seems useful. The percentage energy contributions necessary to serve 50,90 and $100 \%$ of all incidents are plotted as dashed line, as is the kinetic energy associated with more severe contingencies. In Fig. 13, the distribution of kinetic energy available from the aggregate farm studied is plotted with the distribution of energy contributed by the synchronous inertia of the European continental grid.

The duration curve in Fig. 12 indicates that twenty percent of the time the aggregate kinetic energy would be equal to or larger than the that injected during the largest contingency found in the two year history of incidents studied. Forty percent of the time, ninety percent of all events could be covered. Seventeen percent of the time, no energy is available. By comparing the distribution of events with the distribution of energy, it can be further noted that thirty seven percent of the time, the minimum available kinetic energy reserve is 


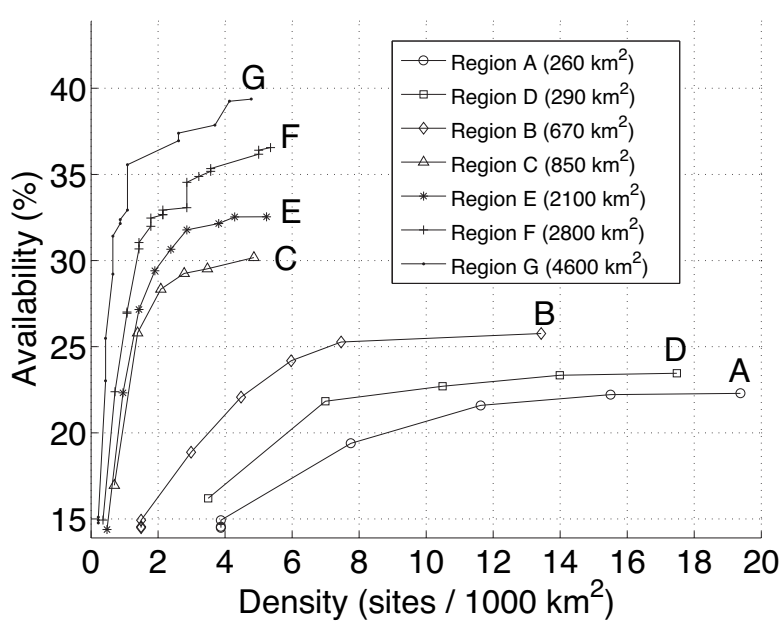

(a) Family of fixed offshore areas.

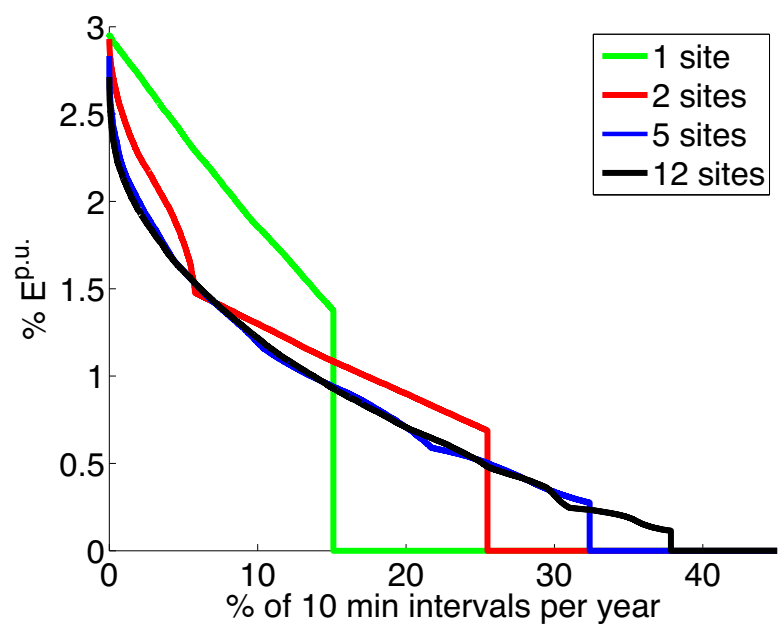

(b) Family of kinetic energy duration curves, Region G.

Fig. 10. Dependence of kinetic energy availability on density of sites.

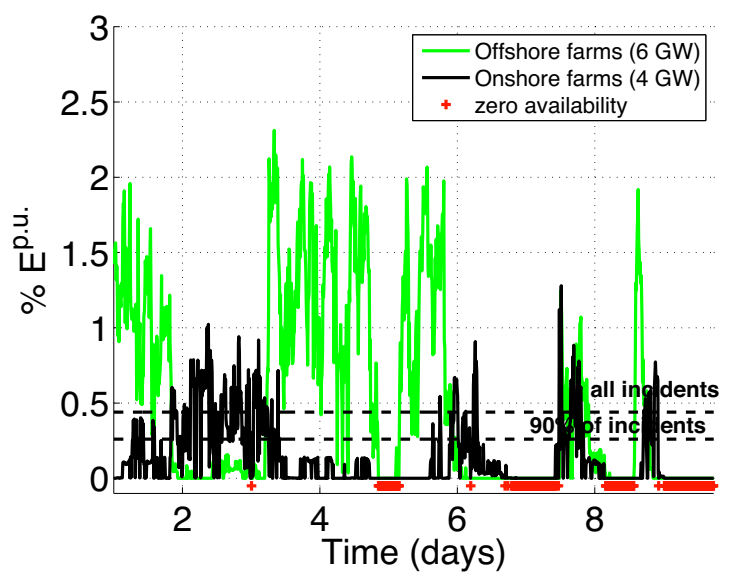

Fig. 11. Kinetic energy available from offshore farms and onshore farms over 10 days.

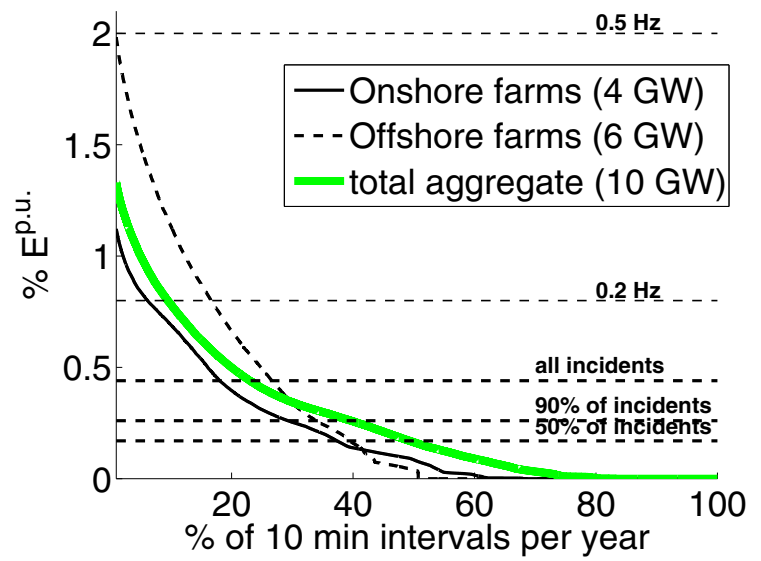

Fig. 12. Duration curves of offshore farms, onshore farms and total aggregate. Horizontal lines indicate energy contributed by synchronous machines into frequency drops of different sizes.

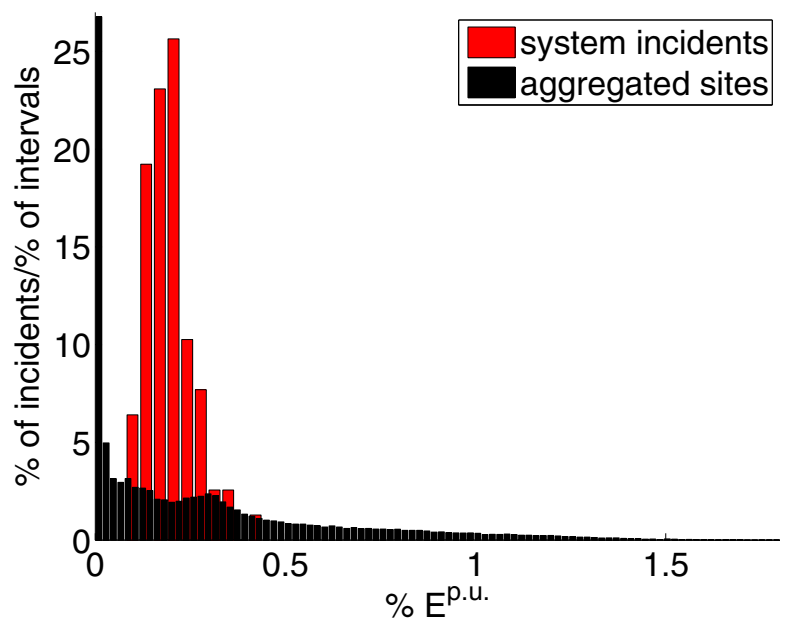

Fig. 13. Distribution of available aggregate kinetic energy from farms, and of kinetic energy contributed by synchronous machines in transients within the European continental system. All values in percent of kinetic energy at rated speed.

insufficient to contribute properly to any of the incidents.

\section{Applications for a Smart Grid}

A smart grid might help system operators to validate models of the aggregated resource and better understand its characteristics before they attempt to integrate it into regular operation. Farms participating on a trial basis could provide valuable demonstrations of the concept. A better understanding might lead to optimized approaches to maintaining kinetic energy reserve in wind farms. In particular, it would be easier to exploit geographic diversity and minimize the amount of energy thrown away due to de-rating if extensive measurements and communication were available.

Moving beyond concept, a smart grid could be useful when implementing a more flexible approach to assessing and procuring the amount of kinetic energy reserve needed. A grid with smart features would be used to construct and deliver up-to-date and forecasted information about the resources, and 
facilltate more regularly updated short-term forecasts. It would also convey the current value of kinetic energy on a reserve market. Finally, the ability to monitor and communicate with a large number of parties would also be required to confirm the delivery of kinetic energy, and to communicate either penalties or payment.

\section{CONCLUSIONS}

As an aggregate resource, the kinetic energy offered by distributed wind farms can not be depended upon at all times, but it is of similar size to the amount of kinetic energy delivered from a synchronous machine of equal power capacity during contingencies. Forty percent of the year, the quantity of kinetic energy present is sufficient to contribute as much as or more than a synchronous machine to $90 \%$ of all contingencies. However, for another forty percent of the year, the quantity is insuficient for any contingency.

The amount of kinetic energy available can often exceed the minimum amount promised by a factor of two or more, due to the uncertainty of wind speeds. In contrast, synchronous generators do not vary in the amount they can provide. The standard deviation approach taken is reasonable but conservative, and a detailed understading of the reserve within 10 minutes should come next.

Improvements in availability due to pooling spatially separated sites was investigated. It was found that the benefit of site separation diminishes for distances greater than $50 \mathrm{~km}$. It was also found for areas greater than one thousand square kilometers, increasing the density of sites has a more dramatic impact on availability than increasing the area. However, beyond a density of two sites per thousand kilometers, increasing density becomes less effective in increasing availability.

This work has examined technical potential of an aggregated resource of distributed wind turbines to provide kinetic energy reserve. It has not investigated the issue of forecasting, monitoring, and otherwise implementing such a resource. The quantity of energy seems worth pursuing, but it is evident that significant information infrastructure would be necessary to characterize and manage the resource. The concept thus offers interesting applications for smart grid technologies and pilot projects.

\section{ACKNOWLEDGEMENTS}

Authors gratefully acknowledge the Dutch TSO TenneT for provision of frequency contingency data, and the Dutch Meteorological Institute for provision of original measured wind speed timeseries.

\section{REFERENCES}

[1] International Electrotechnical Commission. IEC 61400-1, Wind Turbines - Part 1: Design Requirements. Wiley, 2001.

[2] J. Ekanayake and N. Jenkins. Comparison of the response of doubly fed and fixed-speed induction generator wind turbines to changes in network frequency. IEEE Transactions on Energy Conversion, 19(4):800-802, 2004.

[3] M. Gibescu, A. Brand, and W. Kling. Estimation of variability and predictability of large-scale wind energy in the netherlands. Wind Energy, 12:241-260, 2009.
[4] P.K. Keung, P. Lei, H. Banakar, and B.T. Ooi. Kinetic energy of windturbine generators for system frequency support. IEEE Transactions on Power Systems, 24(1):279-287, 2009.

[5] Prabha Kundur. Power System Stability and Control. McGraw-Hill, 1997.

[6] M. O'Malley R. Doherty, G. Lalor. Frequency control in competitive market dispatch. IEEE Transactions on Power Systems, 20(3):15881596, August 2005.

[7] B. Rawn, M. Gibescu, and W.Kling. A static analysis method to determine the availability of kinetic energy from wind turbines. In IEEE Power Engineering Society General Meeting, July 25-29 2010.

[8] F. Shewarga and I. Erlich. Impact of large offshore wind farms on power system transient stability. PSCE Seattle, 2009.

[9] J. G. Slootweg, H. Polinder, W. L. Kling, and J.A Ferreira. Representing wind turbine electrical generating systems in fundamental frequency simulation. IEEE Transactions on Energy Conversion, 18(4):516-524, December 2003.

[10] G. Tarnowski, P. Kjaer, P. Sørensen, and J. Østergard. Study on variable speed wind turbines capability for frequency response. In Proceedings of the 2009 European Wind Energy Conference, 2009.

[11] E. Welfonder, R. Neifer, and M. Spanner. Development and experimental identification of dynamic models for wind turbines. Control Engineering Practice, 5(1):63-73, 1997.

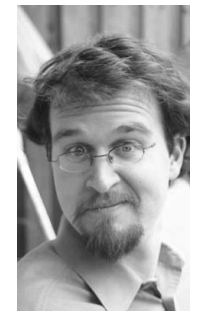

Barry G. Rawn received the $\mathrm{PhD}$ degree in electrical engineering from the Department of Electrical \& Computer Engineering at the University of Toronto, where received the BASc and MASc degrees in Engineering Science and Electrical Engineering respectively from the University of Toronto in 2002 and 2004. His research interests include nonlinear dynamics and sustainable energy infrastructure. $\mathrm{He}$ is currently a postdoctoral researcher in the Electrical Power Systems group at the Delft University of Technology, The Netherlands.

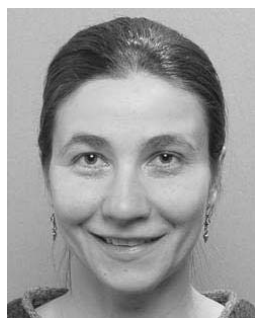

Madeleine Gibescu (M05) received the Dipl.Eng. in power engineering from the University Politehnica, Bucharest, Romania in 1993 and her MSEE and $\mathrm{Ph} . \mathrm{D}$. degrees from the University of Washington, Seattle,WA, U.S. in 1995 and 2003, respectively. She has worked as a Research Engineer for ClearSight Systems and as a Power Systems Engineer for the AREVA T\&D Corporation. She is currently an Assistant Professor with the Electrical Power Systems group at the Delft University of Technology, The Netherlands.

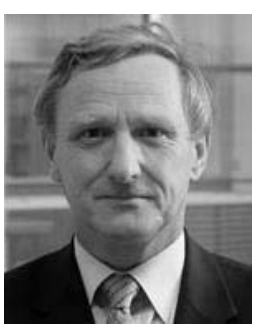

Wil L. Kling (M95) received the M.Sc. degree in electrical engineering from the Eindhoven University of Technology, the Netherlands, in 1978. From 1978 to 1983 he worked with Kema, from 1983 to 1998 with Sep and since then up till the end of 2008 he was with TenneT, the Dutch Transmission System Operator, as senior engineer for network planning and network strategy. Since 1993 he is a part-time Professor at the Delft University of Technology and since 2000 also at the Eindhoven University of Technology, The Netherlands. From December 2008 he is appointed as a full Professor and chair of Electrical Power Systems group at the Eindhoven University of Technology. He is leading research programs on distributed generation, integration of wind power, network concepts and reliability issues. Prof. Kling is involved in scientific organisations such as Cigr and IEEE. He is the Dutch representative in Study Committee C6 Distribution Systems and Dispersed Generation and the Administrative Council of Cigr. 